\title{
Belarusian Olympiad in Informatics
}

\author{
Iryna KIRYNOVICH ${ }^{1}$, Aliaksei TOLSTSIKAU ${ }^{2}$ \\ ${ }^{1}$ Faculty of Computer-Aided Design, Belarusian State University \\ of Informatics and Radioelectronics \\ Brovki 6, Minsk, Belarus, 220013 \\ ${ }^{2}$ Faculty of Applied Mathematics and Computer Science, Belarusian State University \\ Nezavisimosty Ave. 4, Minsk, Belarus, 220030 \\ e-mail:kirinovich.irina@yandex.ru,tolstikov@bsu.by
}

\begin{abstract}
Olympiad in Informatics has been held in Belarus since 1988 and is a high priority direction in the work with gifted students. National Olympiad in Informatics consists of four stages. It is the most popular intellectual competition among youth in the Republic of Belarus.
\end{abstract}

Keywords: Olympiad in Informatics, trainings, selection for international competition, International Olympiad in Informatics, IOI.

\section{Introduction}

In 2016 the XXIX Belarusian Olympiad in Informatics was held in Mogilev, Belarus. Belarusian team has taken part in IOI since 1990, when the II International Olympiad in Informatics was held in Minsk. For 26 years the Republic of Belarus was represented by 63 members who were awarded by 79 medals (gold 14, silver 33, and bronze 32). ${ }^{1}$

Participation in the International Olympiads is the final step of multi-stage competition among gifted students. Participants of the first selection and training camp are determined during the final round of the national contest. In 30 days teams of the Republic of Belarus prepare for participation in IOI, IMO, IPhO, IChO, IBO. The national contest and the preparation for international competitions are provided by employees and students of the leading universities

National Olympiads are organized by the Ministry of education of the Republic of Belarus.

The winners (Fig. 1) of the final stage of the competition have the opportunity to enroll in the state universities without exams.

\footnotetext{
${ }^{1}$ http://stats.ioinformatics.org/countries/BLR
} 


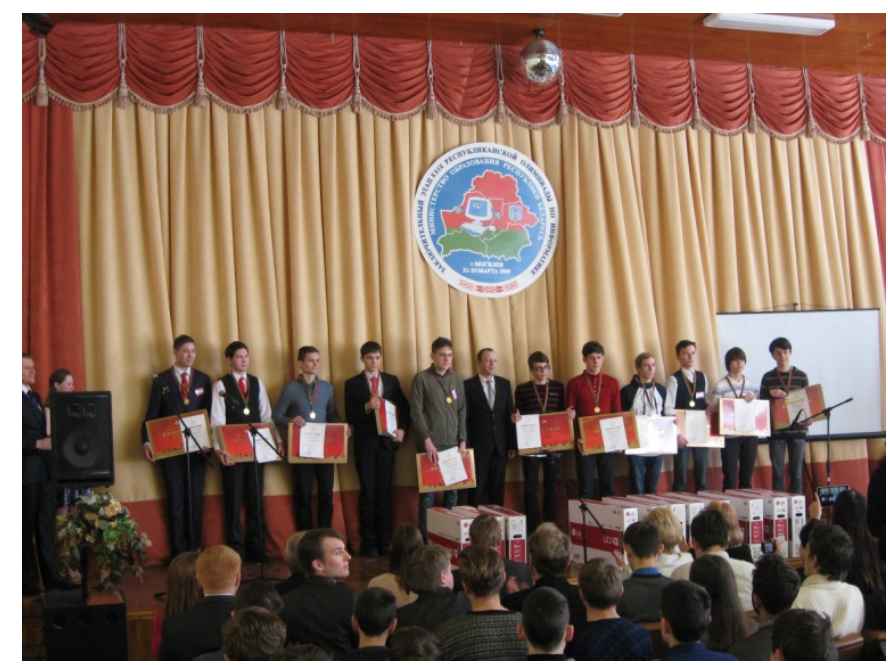

Fig. 1. The final stage of the Belarussian Olympiad in Informatics in 2016 - winners of the 1st degree diplomas. Head of Department of education of regional Executive Committee Vladimir Ryzhkov is standing in the middle of the photo.

\section{National Belarusian Olympiad in Informatics}

National Olympiad in Informatics is held with the aim of identifying and improving the capabilities of the gifted students in the field of informatics and programming. The main goals of the National Olympiad are to increase interest in learning programming, to deep their theoretical knowledge and practical skills, to prepare students for participating in the international competitions. Participation in all stages of the Olympiad is free for students.

National Olympiad is held in each academic year in four stages: the first stage is the educational establishment level, the second stage is the district (city) level, the third stage is the regional competition, the fourth stage is the final national round.

Problems of three types are used at the stages of the National Olympiad in Informatics; each of them requires developing an algorithm for the problem and implementing it in one of the available programming languages $(\mathrm{C}++$ or Pascal). The problem of the first type is the classic one: contestant has to write a program that reads the input and produces the answer, i.e. the contestant doesn't know which test data will be used to check his program. The problem of the second type is a question with open tests. In problems of this type participants have all input data, and it is necessary to provide the results of the solution for known test data.

Solution grading for the second type problems usually uses partial scoring, the solution is compared with the optimal or best solution among all participants of the contest. The problem of the third type is the interactive one. In problems of this type the source code of a participant interacts with unknown to him library. Solutions obtain input and the list of actions that should be performed using known protocol. These problems allow 


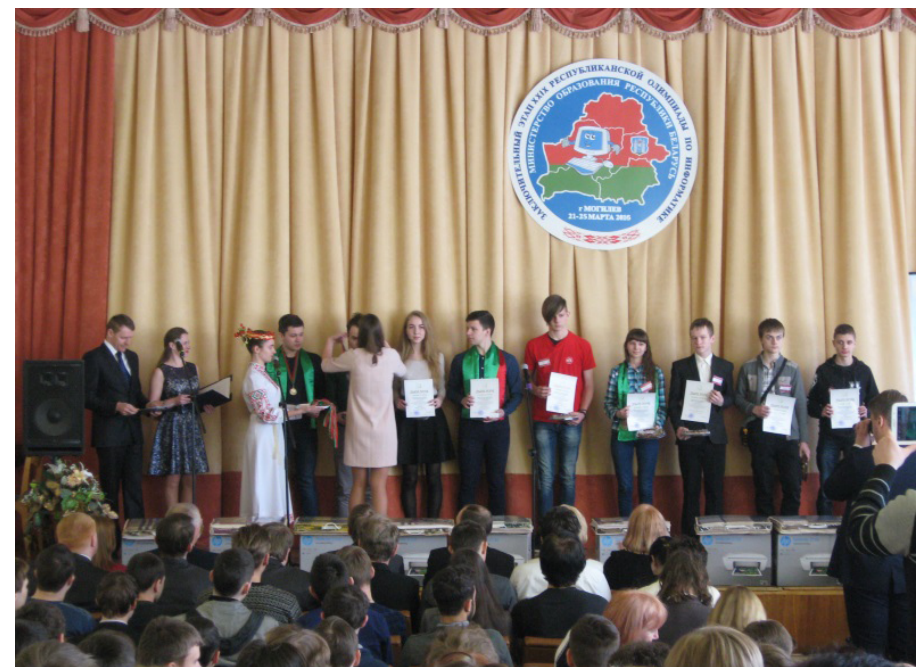

Fig. 2. Awarding 3rd degree diplomas and medals to the holders of the final stage of the Belarussian Olympiad on Informatics 2016.

using questions required processing of input data in real-time, games, tasks, "black box" interaction etc.

Between the stages of the Olympiad training camps are held to prepare students to participate in the future stages of the competition.

The winners of each round of the Olympiad are awarded with I, II, and III diplomas (Fig. 2). The number of winners at each stage of the contest does not exceed $45 \%$ of the number of participants. The number of I diplomas does not exceed $20 \%$ of the number of winners. Share of II diplomas is no more than 30\%, III diplomas - no more than $50 \%$. The actual number of winners at each stage is determined by the jury.

\subsection{First and Second Stages}

The first stage of the National Olympiad should be held not later than November of the current academic year and is an internal stage in each institution of the Republic of Belarus. At this stage all interested students take part in the competition. The best students qualify to participate in the second stage of the Olympiad in accordance with the established quota. The problems preparation for this stage is not kept centrally so each institution determines the format and prepares questions independently.

The second stage is the city or district level. At this stage the contest is held no later than December of the current academic year and consists of one practical exam. The contest problems for the second stage of the Olympiad are prepared centrally by each regional department of education and contain usually only the classic problems. After the second stage of the Olympiad each district forms a team to participate in the third stage of the Olympiad. 


\subsection{Third Stage}

The third stage of the National Olympiad is held in each region of the Republic of Belarus ( 7 in total). All participants compete on the same problem set prepared by the Ministry of education of the Republic of Belarus. The problem of the second type (open tests) adds to the classic problems at this stage. The competition is held in 2 practical exams, each of them requires solving 3-4 questions. The problem complexity is significantly higher at this stage than at the previous one.

Each region forms a team of 15 students to perform at the final stage. In addition, the team may be expanded at the expense of the last year contest winners (final stage), who won diploma this year (third stage), but was not ranked in the top 15 in the region, as well as the winners of the International Zhautykov Olympiad (Kazakhstan).

In January/February each regional team receives additional training camp for 14 days to prepare for the final stage. Students listen to the theoretical lectures on constructing algorithms, how to use data structures in the efficient way, and various branches of mathematics and computer science. In addition to theoretical studies there are practical exams with analysis.

Team of the Lyceum of the Belarusian State University participates in addition to the seven regions of the Republic of Belarus in the final stage of the Olympiad.

\subsection{Final Stage}

The final stage of the National Olympiad is carried out by the Ministry of education within 5 days in one of the host cities in March/April (Table 1). The contest problems at this stage contain the interactive task in addition to the classical and open tests.

In the National Olympiad in Informatics all students shares a common rank list regardless of grade (Table 2). About $50 \%$ of the participants of the final stage of the Olympiad are graduates of secondary schools, gymnasiums and lyceums.

All students (grade 11) who won the final stage are eligible for admission to the state universities of the Republic of Belarus without exams.

\section{Preparation for International Competitions}

According to the results of the final stage of the National Olympiad the list of 10-12 most successful students is formed for selection and preparation of the participants of the International Olympiad in Informatics. Camps are held in 2-3 phases with a total duration of 30 days.

At the first phase of the trainings participants compete in from 10 to 15 rounds, the complexity of the problems is close to the international level. After each round analysis is provided by coaches. In addition, training sessions are conducted with rounds of solving different types of problems: object recognition, optimization problems, game problems, etc. The list of the International Olympiad in Informatics participants forms 
Table 1

Number of participants of the final stage in 2012-2016

\begin{tabular}{lllll}
\hline 2012 & 2013 & 2014 & 2015 & 2016 \\
\hline 123 & 123 & 120 & 122 & 120 \\
\hline
\end{tabular}

Table 2

Distribution of participants of the final stage in 2012-2016

\begin{tabular}{|c|c|c|c|c|c|c|c|c|c|c|}
\hline \multirow[t]{2}{*}{ Grade } & \multicolumn{2}{|l|}{2012} & \multicolumn{2}{|l|}{2013} & \multicolumn{2}{|l|}{2014} & \multicolumn{2}{|l|}{2015} & \multicolumn{2}{|l|}{2016} \\
\hline & $\begin{array}{l}\text { Partici- } \\
\text { pants }\end{array}$ & winners & $\begin{array}{l}\text { Partici- } \\
\text { pants }\end{array}$ & winners & $\begin{array}{l}\text { Partici- } \\
\text { pants }\end{array}$ & winners & $\begin{array}{l}\text { Partici- } \\
\text { pants }\end{array}$ & winners & $\begin{array}{l}\text { Partici- } \\
\text { pants }\end{array}$ & winners \\
\hline $6-8$ & 9 & 2 & 5 & 3 & 9 & 4 & 7 & 2 & 7 & 1 \\
\hline 9 & 14 & 5 & 18 & 6 & 14 & 4 & 22 & 8 & 19 & 7 \\
\hline 10 & 43 & 21 & 35 & 12 & 32 & 15 & 29 & 12 & 43 & 22 \\
\hline 11 & 57 & 28 & 65 & 34 & 65 & 31 & 64 & 32 & 51 & 24 \\
\hline
\end{tabular}

after the first camp. The team is approved by the Ministry of education of the Republic of Belarus.

During the next camps coaches make lectures with different topics based on the complex data structures and algorithms, usage of a contest system image provided by IOI organizers and other. Participants continue preparation solving the competitions from other countries and regions. The participation in training camps for students is free. The results of the team of the Republic of Belarus in IOI over the last 5 years are presented in Table 3.

In Belarus operates the high-tech Park, which includes more than 150 resident companies. Every year, the resident companies of the Park of high technologies take part in rewarding winners of the final stage of the Olympiad in Informatics (Fig. 3).

The winners of the final stage of the Republican Olympiad will be awarded with cash prize of the special Fund of the President of the Republic of Belarus for social support of gifted students and shall be included in a national data Bank of talented youth.

The winners of the international Olympiad receive the title of Laureate of the special Fund of the President of the Republic of Belarus for social support of gifted pupils and students.

The presence of this title gives the right to receive a number of social benefits.

Table 3

Performance of the team of the Republic of Belarus in IOI in 2011-2015

\begin{tabular}{|c|c|c|c|c|c|c|c|c|c|}
\hline 2011 & & 2012 & & 2013 & & 2014 & & 2015 & \\
\hline 10 grade & Gold & 11 grade & Gold & 11 grade & Gold & 11 grade & Bronze & 11 grade & Silver \\
\hline 10 grade & Silver & 11 grade & Gold & 11 grade & Silver & 10 grade & Silver & 11 grade & Silver \\
\hline 9 grade & Silver & 10 grade & Silver & 11 grade & Bronze & 10 grade & Bronze & 11 grade & Bronze \\
\hline 9 grade & Silver & 10 grade & Bronze & 11 grade & Bronze & 8 grade & - & 10 grade & Bronze \\
\hline
\end{tabular}




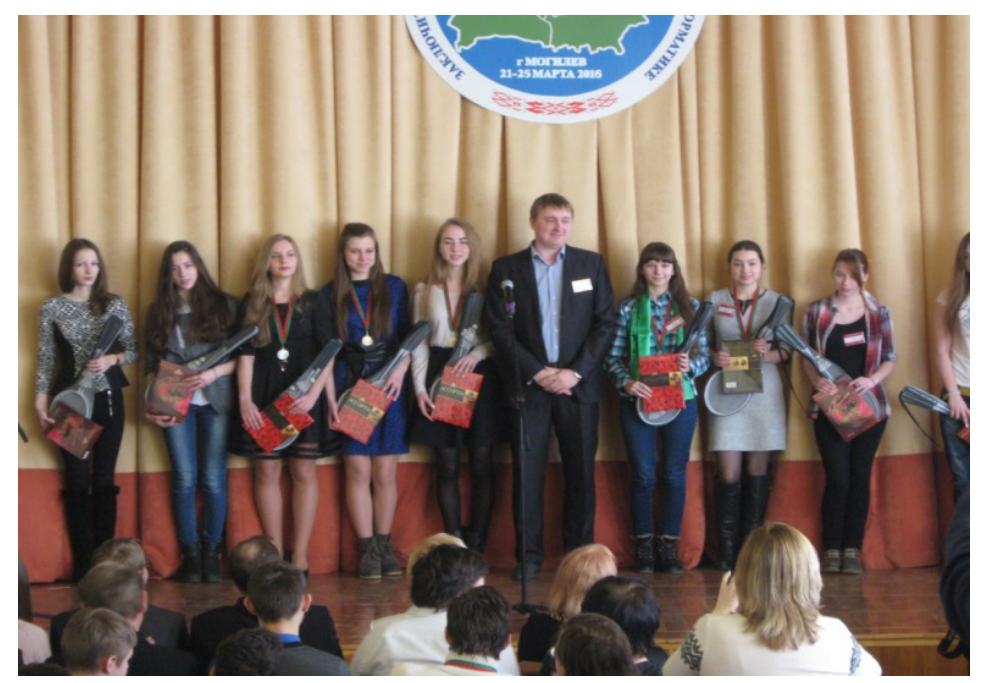

Fig. 3. Nine girls participated in the final stage of the Republican Olympiad on Informatics 2016. Some of them won medals. Director of the company "Yandex Bel" Alex Sikorsky has congratulated the participants.

\section{Conclusion}

This article briefly describes the procedure for conducting the National Olympiad in Informatics in Belarus. Description of all four stages of the competition and the schedule of training and selection camps are provided. In the Republic of Belarus National Olympiad in Informatics is an important and significant event. Belarusian students won lots medals at the international level.

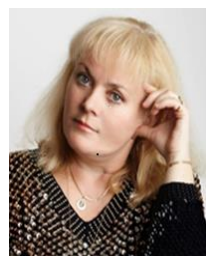

I. Kirynovich, associate professor of the department of engineering psychology and ergonomics, faculty of computer design, Belarusian State University of Informatics and Radioelectronics, PhD in Physics and Mathematics, national coordinator of the Bebras contest in Belarus, the Chairman of the jury of the final stage of the Republican Olympiad in Informatics scientific and pedagogical leader for the preparation team of the Republic of Belarus for participation in the international Olympiad in Informatics.

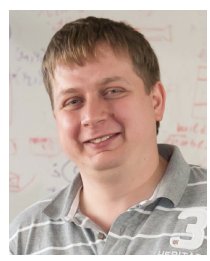

A. Tolstsikau, senior lecturer at Department of computational mathematics, Belarusian State University. Member of the jury of the final stage of National Olympiad in Informatics and various student programming contests. Research interests include parallel and distributed computing, computational complexity theory and algorithms and systems processing large volumes of information. 